\title{
A REAPPRAISAL OF EVALUATION OF FINAL YEAR STUDENT PERFORMANGE
}

\author{
JENNIFER M. HILL B.SC. (PHYSIO) (STELL.) D.T.E. (UNISA) $\dagger$
}

\section{SUMMARY}

The author takes a look at evaluation of the physiotherapy student. She discusses the criteria necessary for evaluation and gives some suggestions as to methods which can be used.

* This paper is a modification of an assignment as part of the D.T.E. (UNISA) course.

+ Was Junior Lecturer, University of Stellenbosch and Tygerberg Hospital. Now Director Oxford Rehabilitation Project, Zimbabwe.

Received 5 March 1980.

\section{OPSOMMING}

Die skrywer gee 'n oorsig van die evaluering van die fisioterapiestudent. Sy bespreek die kriteria wat nodig is vir evalmering en stel metodes wat gebrtik kan word, voor.

As a clinical therapist in a teaching hospital or as a member of the teaching staff, the physiotherapist is regularly called upon to assess the competency of undergraduate students. This is an 'awesome task' (Davis (1979). The average therapist has little background in the theory and methods of student evaluation. Forster and Galley (1978) have presented a useful approach 
to the assessment of clinical competence but the role of evaluation in the training of physiotherapists has not been analysed. This paper represents an attempt to present the curlent thinking on evaluation and the relevancy of these concepts to the physiotherapy situation.

The following questions need to be asked: What is ascssment? Why is it necessary and what is its purpose? In what ways can the student be evaluated? What are the essential characteristics of the measurement techniques?

Grondlund (1976) sees evaluation as applied to education as "a systematic process of determining the extent to which educational objectives are achieved by pupils." This definition is incomplete as it ignoces the learning potential inherent in the test situation. Elbe (1977) says that "learning theory supports tests as a means of providing feedback, a confirmed essential of learning." Taking both these views into account evaluation could be seen as "an ongoing, regular assessment of each student's performance in terms of the objectives and criteria set, so that learning may be facilitated and Fthat both the students' capabilities and the efficacy of the teaching methods may be determined."

\section{USES}

Evaluation can be used for the following purposes:

- To ensure that the curriculum is realistic and adequately taught. If large numbers of students fail electrotherapy, it is unlikely that the students are at fault. It could mean that the objectives need revision or that the teaching is not effective. Clinical therapists and teaching staft have a mutual responsibility to monitor each others' teaching and to report any inadequacy.

- To determine which students are competent to graduate. The university is accountable to society as regards the standards of its graduates. "To the society at large, examinations furnish a guarantee of competence in those examined to perform the tasks demanded of them by the occupation they turn up" (Behr, 1977). The university says to society that $X$ is a safe and effective physiotherapist.

- To provide feedback to the student in order to improve her performance. It is important, especially in the clinical situation, to correct and guide students at regular short intervals. A student should stop using ineffective, misdirected or possibly dangerous treatment methods on her patients as soon as possible.

The available literature reflects conflicting attitudes. Rowntree (1977) sees "assessment primarily as developing the relationship between the student, themselves and the subject matter by giving the students and themselves more inlormation about the present state of the students' understanding; but is incapable of providing valid information about the student to outside parties or about his long term potential to anyone at all." On the other hand, many American authors such as Grondlund (1976) and Pierce (1.977) stress the need for an objective and reliable method of evaluation that enables the students to be accurately graded and ranked. It appears that competition for admission to training centres and for jobs is so great that placement could be dependent on a few extra percent gained in an examination.

\section{OBJECTIVES OF PHYSIOTHERAPY TRAINING}

Before evaluation techniques are chosen the course objectives should be clearly defined and the curriculum should be planned with these in mind.

Bloom defines objectives as "explicit formulations of the ways in which students are expected to be changed by the educative process . . Objectives are not only goals towards which instruction is guided, but they are also the goals that provide the detailed specification for the construction and use of evaluative procedures." (Brown, 1971).

To be of any use objectives must be clear, realistic, measurable and stated in terms of the learner (Mager 1972). The objectives of the physiotherapy course should include changes in the student's behaviour with regard to cognitive (intellectual), aftective (emotional and moral) and motor skills. Each of these skills can be subdivided.

The cognitive domain in learning can be categorised under the headings of knowledge, comprehension, application, analysis, synthesis and evaluation. These range from relatively simple behaviours to more complex ones. The cognitive skills are simplest to evaluate, and of these the more basic ones such as knowledge are the easiest. As cognitive skills are easier to quantify, affective and motor skills are olten neglected and it is possible for a student to be admitted to physiotherapy on the basis of academic achievement alone. Looking at other aspects of evaluation, it can be seen that qualities of the affective domain, such as receiving, responding, valuing, organising and characterisation are important requisites for physiotherapists. So too, are the motor skills which have never been specifically classified but which include a cognitive, al perceptual and a motor component.

In choosing objectives for a training course it is important to use the above classification for it enables one to include all the aspects of learning. Each of the objectives can be achieved by specific methods of teaching and will have a marked influence on the type of evaluation to be used. In fact, the very choice of one technique over another should demonstrate one kind of student ability rather than another. Unfortunately "sometimes the kinds of evaluation procedures available will tend to govern and determine the choice of objectives, contents or methods, rather than to merely ofler additional information to those selecting them on other grounds" (Kelly 1977).

\section{METHODS OF EVALUATION}

"In the past the only universal evaluation technique was the final examination. There is a demand today for more varied types of assessment to meet the variety of aims in teaching, as well as for more evaluation of learning and teaching during the course" (Beard, 1971). This is particularly true of nedical training during which so many types of skills need to be learned and tested. Several authors, such as Fleming (1976) and Herder (1979) have commented on the assessment of medical students.

There are various types of evaluative procedures available. Certain criteria need to be met by these procedures including the problem of stuclent lating.

\section{'TYPES OF EVALUATION (Rowntree, 1977)}

\section{Summative or Formative}

Summative evaluation concerns the grading of students at the end of the course. It is on this basis that students are admitted to university, obtain bursaries and are allowed to practice professionally. It is not part of the learning process although the "threat" of examinations might provide motivation for some students. It is characterised by very little feedback to either the student or, in some cases, to the lecturer, e.g. matriculation examinations. Formative evaluation has as its main purpose "to improve the instructional methods and materials so that greater student learning will occur" 
(Grundlund, 1976). These evaluation methods supply the student with as much feedback as possible as soon as possible.

\section{Frequency, Continuous and Terminal Assessment}

This classification does not necessarily imply that summative evaluation is always terminal or that continuous assessment is always formative. Marks obtained throughout the year can also contribute to, or make up, the final mark. It is possible to combine both methods in order to grade the student. This has the advantage of reducing final examination stress which can easily lead to decreased performance. It also enables a wider spectrun of evaluative procedures to be employed.

\section{Coursework or Examinations}

The student can be evaluated on the work which she has produced during the year, on one terminal examination or on both.

\section{Process or Product}

There is a difference between assessing the tangible results of student work and the way in which the work is produced. The student who gains an increase of 90 degrees range of motion might have achieved a good "product", but if the treatment was very painful her "process" might leave much to be desired. It is vital in physiotherapy that the process be evaluated through the use of e.g. observation or videotape. Process evaluation is more subjective and difficult.

\section{Convergent or Divergent}

Convergent thinkers tend to do very well when focussing on a clearly defined task with no single correct answer. Different forms of evaluation tend to favour different types of thinkers. These questions arise. What type of thinker makes the best therapist? Do physiotherapy teachers encourage different student opinions or are they dogmatic in teaching that there is only one right way of doing things? Do the methods of testing favour those who can reproduce correct answers to problems rather than those who can see varied implications to problems?

\section{TECHNIQUES OF MEASUREMENT}

Different techniques of measurement assess different skills and sometimes more than the desired skills. A long theory paper, e.g. may be intended to test the knowledge of physiotherapy treatments but, "the traditional three hour examination tests the students ability to write at abnormal speed, under unusual stress, on someone else's topic, without reference to his customary sources of information, and with a premium on questionspotting, (and) lucky memorisation" (Rowntree, 1977).

Is this what the physiotherapy teacher wants to test? Here are some suggested techniques.

\section{Knowledge Skills Attitudes}

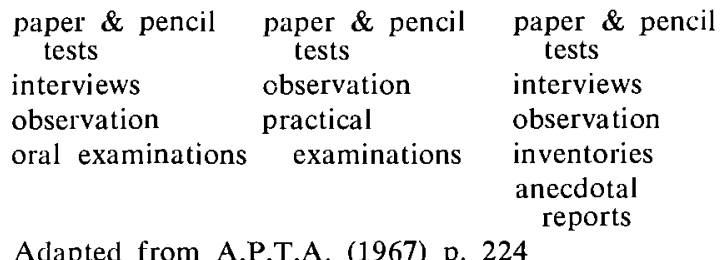

Adapted from A.P.T.A. (1967) p. 224

\section{Paper and Pencil Tests}

Paper and pencil tests are the most used of all tests. They can be used to test either summatively or formatively. They can be done regularly and can form part of the coursework or the examination. Generally these tests measure the product rather than the process.

There are two main types of paper and pencil tests, viz. the short answer/multiple choice test and the essay type test. The first favours objective marking, the second creativity and initiative on the part of the student. If the subject matter is such that there is room for discussion and for differing interpretations of the facts, essay type questions are the most suitable. If the lecturer's main objective is the transfer of his knowledge then multiple choice questions would probably be the best test of whether this objective had been achieved.

Testing of all the different types of intellectual skills should be incorporated into the paper. Questions should be set that require the student to analyse and to evaluate the subject matter or to present new ideas and interpretations. This is difficult as most questions call for purer factual recall.

Physiotherapy treatment papers should become more patient-oriented. Little of the demands of the clinical situation are tested. One seldom sees questions calling for examples of patient evaluation forms or formulation of treatment progress reports for use by other staff members.

\section{Oral Examinations and Interviews}

These tests tend to be more open-ended and subjective. They enable the student to give maximum output in that questions can be modified depending on the student's level of response. These methods are used regularly in the clinical situation when the student is required to report back daily on patients' progress. The clinical supervisor must be aware of the learning potential in this situation. Often the supervisor is unsure of what to look for and what type of questions to ask. $\mathrm{He} / \mathrm{she}$ may not know the best way of aiding the student in the transfer of knowledge from the academic to practical situation. Research into the requirements for student-interviews and -reportback could be useful. The interview is one of the best ways of measuring affective skills. The student's attitude to her patients and her work is best assessed under these conditions.

\section{Observation}

Some skills are impossible to measure through product alone. These, according to Grondlund (1976), include skills such as work habits, social habits, motor skills, scientific attitudes, interests, appreciations and adjustments. Testing of these skills tends to be relatively subjective, but the choice has to be made between using somewhat unreliable methods or not to evaluate these skills at all.

Specific techniques of observation include the use of anecdotal or critical incident reporting. These factual reports of significant incidents in a student's performance include positive and negative behaviour. A number of anecdotes should be collected before drawing inlerences.

Rating scales can be used. A systematic procedure is Lollowed for obtaining and reporting judgements. The rater must not only assess whether quality is present but also to what degree it is present. Despite some disadvantages to this system such as subjectivity, vague formulation of traits and the 'halo-effect' (a student's reputation influences the marks assigned her), "if proper procedures are followed in terms of the construction, training of raters, administration and analysis, rating 
scales may be the best method available to obtain information in the skill area" (A.P.T.A., 1967).

A combination of anecdotal reporting and rating scales is often used in clinical assessment but the approach to anecdotal reporting is often informal and undisciplined.

Checklists can also be used as guidelines for observation. They consist of words describing specific behaviours which can be ticked off while watching the student at work. Checklists are useful because they can teach both supervisor and student what to look for in patient treatment.

\section{Practical Examinations}

Practical examinations incorporate all the observation skills. Both the student and the examiner should know what is being tested and what the criteria for success are.

A wide range of techniques and conditions can be tested but patient feedback is lacking. Care must be taken that students do not become mere technicians because of overemphasis on the practical and not enough on the patient. This situation can be avoided to a certain extent by the introduction of 'Paper-patients'. The student is not confronted with an amorphous 'Parkinsons Disease', but is presented with a defined patient with specific problems. This moves the emphasis from memory work to logical reasoning.

\section{Projects and Classwork}

Projects and classwork can cover a wider variety of skills than is possible in the examination situation. They are also realistic as books and resource people can be consulted. They test the whole range of cognitive functions and are ideal for the divergent student. She learns to research privately and it should enable her to become constructively critical of existing 'dogmas'.

The danger of using projects as a testing method lies in the subjectivity of the marker. Criteria should be clearly spelt out and distributed to both students and staff members with a standard system of marking.

\section{Peer and Self Assessment}

In some hospitals a system of patient care audit and peer review has been instituted along the lines suggested by Khan (1976). Unfortunately peer-and self-assessment has not received much attention in the training of therapists. By introducing self-assessment in clinical work the faculty would not only obtain useful information about the student but the student will become constructively self-critical. On graduation the student becomes responsible for herself and her standard of patient care. Self-appraisal could prepare her to constantly challenge the quality of her work.

\section{ESSENTIAL CHARACTERISTICS OF MEASUREMENT DEVICES \\ Objectivity}

To satisfy this requirement a general agreement must be reached about the standard of the student's response by everyone qualified to assess it. Some tests, as shown above, are more objective than others but, by stating specific objectives and criteria for each situation, uniformity can be obtained.

\section{Reliability}

"A reliable test measures consistently and accurately each time it is used. It's results are not unduly influenced by chance" (Brown and Thornton, 1971).

\section{Validity}

This may be the most important characteristic of a test. Does it measure the type of behaviour which is required? A valid test should measure the exact degree to which the stated objective has been achieved. For example, a question is set with the aim of testing the application of the principles of neuro-developmental therapy (N.D.T.) to the treatment of an athetoid child. In answering the student could have memorized the reply (memory is being tested), the student could be short of time and unable to finish the paper (speed of writing and thinking being tested), the question could be formulated in such a way that the student is unable to understand what is required (interpretation of language being tested) etc.

Despite the difficulties, validity is an essential aim. "In the final analysis the validity of test results is based on the extent to which the behaviour elicited in the testing situation is representative of the behaviour being tested" (Kelly, 1977).

\section{Practicality}

Practicality includes such considerations as economy of time, ease of administration, scoring and costs. A balance between practicality and validity is sometimes difficult to achieve.

\section{Discrimination}

The test procedure must be able to discriminate between those who have achieved the objectives set and those who have not.

\section{GRADING}

Grading in physiotherapy is generally done according to the objectives set rather than according to the norm (grading by the normal distribution curve). A problem occasionally arises in terms of the relative value of the year mark and the final examination mark. Should the student fail on the grounds of: a poor performance in her final examination when she has regularly achieved reasonable marks during the year? If so, is the final examination valid? If not, what is the purpose of the final examination? Similarly, can external examiners fail students that the internal examiners would like to pass and vice versa?

It could be that the purpose of the final examinations is not well enough defined. The following could be taken as the goals of the terminal examination:

- To assess the standard of the department, the teaching and the syllabus.

- To motivate the students to consolidate the body of. knowledge before leaving university.

- To enable the poor student to improve his/her marks.

In other words, the examination is insufficient in terms of determining the average student's capabilities and the year mark, which is made up of class tests, projects and clinical reports, is seen to be a more valid reflection of the student's ability to practice as a therapist.

\section{CONCLUSIONS AND SUGGESTIONS}

The physiotherapy student is comprehensively assessed during her training but certain areas could be improved. Here are a few suggestions.

\section{Theory Papers}

These are used at present to test cognitive skills. They could be modified to include the assessment of 
written communication skills and to capitalise on the learning potential of the test situation. A typed set of model answers could be distributed on conclusion of the test. (It is understood that other answers would be acceptable and welcomed if correct.)

\section{Clinical Reports on Student Performances in the} Hospital

These are the most valid tests of a student's ability as al therapist but they tend to be subjective. More guidance on specific methods is needed.

Clinical work could also be assessed by the student. She should be called upon to write a report on her own work as well as commenting on the supervision that she was given.

\section{Clinical Examinations}

At present it would appear that examination of the patient and treatment planning are not assessed. It might be constructive to include a patient evaluation done in the presence of the examiner.

\section{Practical Examinations}

These tests could be made more meaningful and valid if 'paper-patients' rather than conditions were presented. The importance of tests should be de-emphasised.

Projects seem to be receiving more attention. It should be stressed that research is not confined to stuclent life and that in practice every patient can provide information for improving and investigating treatments.

The profession, and more especially the teaching hospitals must strive to find more valid, reliable, objective and practical ways of testing students. In this way the quality of the graduates can only increase and the profession will truly be able to take pride in the standard of patient care delivered.

\section{REFERENCES}

Anterican Physical Therapy Association (1967). Hand book for physical therapy teachers. A.P.T.A. New York.

Beard, R. (1971): Research into teaching methods in higher education. 2nd Ed. Society for Research into Higher Education, London.

Behr, A. L. (1977): A textbook of educational method. 2nd Ed. J. L. van Schaik. Pretoria.

Brown, J. W. and Thornton, J. W. (1971). College teaching; a systematic approach. MacGraw-Hill. New York.

Davis, C. M., (1979). Competency: The what, why, and how of it. Pliys. T/ier., 59, $1088-1094$.

Elbe, K. E. (1977). The craft of teaching. Jossey-Bass. San Francisco.

Fleming, P. R. et al. (1976). Examinations in medicine. Churchill-Livingstone. Edinburgh.

Galley, P. and Forster, A. (1978). Assessment of professional competency. Alust. J. Physio., 24, 53-59.

Grondlund, N. E. (1976). Measurement and evaluation in teaching: 3rd ed. MacMillan. New York.

Herder, R. M. (1979). Assessment of clinical competence using an objective structured clinical examination. Med. Ed. 13, 41 - 54.

Khan, A. U. and Howroyd, H. A. (1976). Physiotherapy care audit and peer review. Phys Canad, 28, $163-167$.

Kelly, A. V. (1977). The curriculum: theory and practice. Harper and Row. London.

Mager, R. F. (1962). Preparing instructional objectives. Fearson Publishers, 1nc. Palo Alto.

Pierce, W. D. and Lorber, M. A. (1977). Objectives and melhods for secondary teaching. Prentice-Hall. Englewood Cli.is.

Rowntree, D. (1977). Assessing students: How shall we know them? Harper and Row. London.

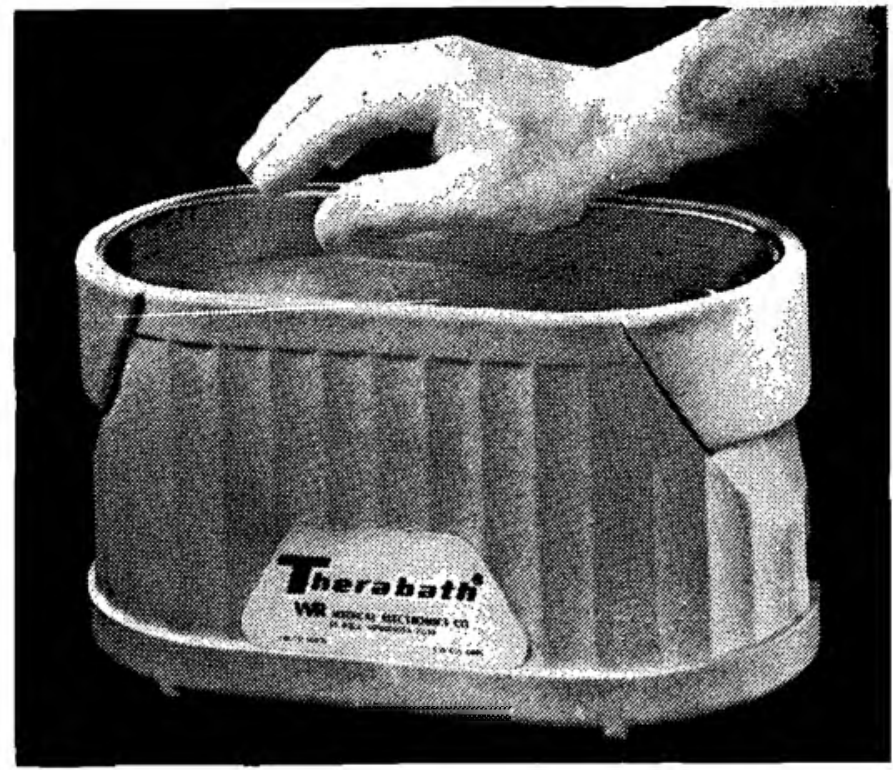

\section{THE THERABATH}

a light, portable, economically-priced Wax Bath

Therabath provides effective paraffin heat treatment for arthritis, chronic joint inflammation, stiffness, muscle spasm and athletic or other injuries. Hands, feet or elbows are immersed paraffin is brushed on other areas. Thermostatically controlled to hold the special Theraffin wax at a beneficial $52^{\circ} \mathrm{C}-54^{\circ} \mathrm{C}$. Portable for use anywhere. Uses less than 25 watts of electricity; operates for less than ten cents a day. Initial supply of Theraffin wax included.

Price R147,50 including wax plus G.S.T.

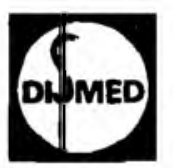




\section{CORRESPONDENCE}

Dear Madam,

\section{Introductory Circulars and Directory of Private Practitioners}

Permit me through the medium of your Journal to explain a few facts which pertain to the somewhat controversial matters mentioned above.

Introductory Circulars:

This refers to information which physiotherapists starting in private practice are permitted to circularise to doctors, medical institutions and hospitals according to Government notice No. R 1838 of 16 September 1977. It is generally acceptable that a notification of the name, address and telephone number of a new private practitioner, or changes in an existing practice may be circulated to doctors. Our Association felt, however, that more information is sometimes necessary in order to facilitate patient selection and correct referral by general practitioners. It was therefore agreed by the South African Society of Physiotherapy and accepted by the Professional Board for Physiotherapy that certain "special interests" may be named. The list of approved interests included spinal and peripheral mobilisation/manipulation. Specific "schools" may be mentioned e.g. Cyriax, Maitland etc. This also applies to neurology (Bobath etc.). This was done as an interim measure to acquaint doctors with current schools of thought in physiotherapy, until such a time as a specialist register may be established in respect of the physiotherapy profession,

The Directory of Private Practitioners:

This is sent to all medical practitioners and orthopaedic and other specialists. The same items of special interest are used here for their information, in order to facilitate referral to the physiotherapist in their area who is able to offer the treatment required. This is, of course, not limited to manipulation but includes areas such as IPPV treatments, ante-natal instruction and gymnasium facilities. Physiotherapists are allowed to limit their practice to specific fields such as obstetrics, chests or neurology where an adequate pool of "general physiotherapists" is available i.e. in the larger centres. These special interests are not comparable to medical specialities at present, and the qualifications are not registrable.

I acknowledge that the position at present is not ideal, but I submit that it is workable as an interim measure. Certain recommendations have been forwarded by our Association to the South African Society of Physiotherapy and the S.A. Medical and Dental Council for approval, which should in the long term improve matters.

I hope this clears up these matters somewhat:

MISS B. WINTER

Hon. Secretary (Private Practitioners Association)

\section{NUWE LYS VAN GEREGISTREERDE} MEDIESE SKEMAS

Bogenocmde lys is in Staatskoerant No 7404 van 13 Februaric 1981 gepubliseer.

\section{NEW LIST OF REGISTERED} MEDICAL SCHEMES

The above list has been published in Government Gazette no. 7404 of: 13 February 1981.

\section{P.P.A. EXECUTIVE COMMITTEE}

At the Annual General Meeting held in Johannesburg on 26 March 1981 the following were elected:

President: Mr: W. E. G. Vaughan

Chairman: Mr. P. Kilbey

Ist Vice chairman: Mrs. P. Swilling

2nd Vice chairman: Mr A. Weil

Honorary Secretary: Miss B. Winter

Honoraly Tieasurer/Registrar: Mr. J. Jaakke

Honorary Advertising Manager: Mrs G. Botha

Miss S. Oosthuizen is Honorary Life President and all Branch Chairmen are ex-cflicio members of the Executive Committee.

Mrs Pilkington was made an Honorary Lile Member.

\section{NEW APPARATUS}

Electro-Medical Supplies (Greenham) Limited of Wantage, United Kingdom, have developed a new ultrasonic therapy unit, the EMS Therasonic 1.030 on which they supply the following information. The Therasonic 1030 is a technically advanced ultrasonic therapy unit and provides the Physiotherapist with a complete range of treatment facilities for this modality. It incorporates the following features. 'Two operating frequencies $1 \mathrm{MHz}$ for a cleeper penetration of tissuc (approxmaely $50 \%$ reduction in energy at a depth of $5 \mathrm{~cm}$ in human solit tissue) and $4 \mathrm{MHz}$ with an approximately $50 \%$ reduction at a depth of $1,5 \mathrm{~cm} .3 \mathrm{MHz}$ is therefore indicated for sports injuries and scar tissue treatments. By incorporating the latest electronic construction techniques it has been possible to provide these two outputs of 1 and $3 \mathrm{MHz}$ from the one frequency head and the one crystal.

Frequency selection is carried out by depressing illuminated buttons on the control panel. There is no necessity to change treatment heads or crystals to elfect at change of frequency.

Output which is continuously variable is indicated on a clirect reading output meter showing both the total watts and the watts per sq. $\mathrm{cm}$ being delivered to the patient.

An illuminated digital treatment timer is incorporated which gives the operator immediate indication of: the time left for a particular treatment to be concluded.

As mentioned previously there are 3 pulsed ratios of $\mathrm{I}: 2,1: 4$ and $1: 7$ available in the pulsed mode on the Therasonic 1030 .

A lightweight, ergonomically-designed treatment hoad is incorporated which houses the special twin-lirequency crystal; this can be used in a pen grip or within the palm of the hand and is extremely easy and comfortable to use and apply.

The Therasonic 1030 which is built to the latest world salfety standards, has a stainless steel control panel, illuminated contiol buttons and an uncluttered clear layout.

A panel socket is fitted to enable any make or type of miscle stimulator to be plugged into the Therasonic 1030 so that a combination output may be used consisting of ultrasonic and a low frequency or diadynamic waveform (e.g. exponential currents, faradic stimulation, square wave galvanism, diadynamic therapy, etc.).

Sole distributors in the Republic of South Africa are Medical Distributors (Pty) Limited. 